Ethiopian Journal of Environmental Studies \& Management 7 Suppl.: 754 - 764, 2014.

ISSN:1998-0507

doi: http://dx.doi.org/10.4314/ejesm.v7i1.6S

Submitted: August 11, 2014

Accepted: November 04, 2014

\title{
PERFORMANCE OF ENVIRONMENTAL IMPACT ASSESSMENT (EIA) REGIME IN TANZANIA
}

\author{
*NYIHIRANI, F., ${ }^{1}$ KATIMA, J.H.Y. ${ }^{2}$ AND MBULULO, Y. ${ }^{3}$ \\ ${ }^{1}$ Centre for Environment, Poverty and Sustainable Development, Institute of Development \\ Studies, Mzumbe University, Box 1 Morogoro, Tanzania \\ ${ }^{2}$ College of Engineering and Technology, University of Dar es Salaam, Tanzania \\ ${ }^{3}$ Faculty of Science, Sokoine University of Agriculture, Morogoro, Tanzania
}

\begin{abstract}
Tanzania enacted the Environmental Management Act (EMA) in 2004 with Environmental Impact Assessment (EIA) as one of its major tools for protecting environment from the impacts of development projects. According to EMA, all new projects have to undertake EIA before they are commissioned. This paper assesses to what extent this has been achieved. The study involved 5 industries (as cases) which have Environmental Certificates, staff of the National Environment Management Council (NEMC) which is responsible to enforce EMA, Municipal Councils, Wards, Registered Environmental Consulting Firms and NGOs. The assessment focused on institutional strength and weaknesses, awareness of industrial staff and resources allocation for implementation of the Environmental Management Plan (EMP) and Environmental Monitoring Plan (MP). The assessment was done through reviewing Environmental Impact Statement (EIS), site observation, interviews and questionnaires. Study findings show that to a greater extent, EMPS and MPS as presented in EIS are not implemented due to existence of institutional weaknesses, low awareness, poor allocation of resources for EMP implementation and weak enforcement. It was thus concluded that; EIA process apart from identifying potential impacts, it does not go all the way to ensure that they are mitigated. The paper proposes recommendations to remedy the situation.
\end{abstract}

Key Words: Performance, Industries, Environment, Impact, Certification, Tanzania

\section{Introduction}

EIA is an important environmental management tool especially when considering mitigation of negative impacts associated with industrialization. Internationally, the concept of EIA was first put into practice in the United States with the passage of National Environmental Policy Act in 1969 (Kiely, 1998). Since then several countries have adopted EIA in some form of legislation and /or policy, therefore it is a worldwide adopted tool (Androulidakis and Karakassis, 2006; Pölönen et al., 2011;
*Corresponding Author: Nyihirani, F.

Email: fnyihirani@mzumbe.ac.tz
Marara et al., 2011). In Tanzania, EIA has been incorporated in the National Environmental Policy (URT, 1997); and the EMA (URT, 2004).

The industries are among projects listed in EIA and Audit Regulations (URT, 2005) to which EIA is mandatory. The Regulations set conditions for obtaining license to projects mandated to conduct EIA. Pölönen et al. (2011) saw these preconditions as the necessary tool to prevent significant negative effects on the environment. Before enactment of EMA in Tanzania, only few projects 
conducted EIA as fulfilment of conditions imposed by financial institutions for the project to be supported (Tesli, 2003; Marara et al., 2011; Katima, 2008). A number of studies (Ramjeawon and Beedassy, 2004; Albina, 2008; Sosovele, 2011) suggest that, legal status of EIA caused an increase in number of projects that conducted EIA studies. Therefore, increase in significant adverse impacts was expected to be reduced since EIA is intended to provide measures to reduce or mitigate environmental destruction (Sadler, 1996; Tesli, 2003). However, this is not the case as there are a number of complaints concerning environmental problems from people who are living close to those projects with EIA certificates. Studies by Curran et al. (1998) and Hazell and Benevides (2000) revealed that gradual increase of nuisance cases reflects unsatisfactory practice of EIA. This is because projects change substantially after authorization as developers deliberately avoid guidelines at the latter stages of the impact assessment process, particularly in implementation of mitigation measures and subsequent monitoring (Sadler, 1996; Ahmad and Wood, 2002). Therefore, EIA implementation after approval condition is a challenge to EIA system (O'Faircheallaigh, 2007) and the gaps in legislation and practices weaken its performance in mitigating adverse impacts from development projects (Pölönen et al., 2011). This study therefore assessed implementation of EIA recommendations after certification.

\section{Study Area}

This study was conducted in Dar es Salaam which is Tanzania's largest coastal region (city) located on the east coast of Tanzania. It lies between latitude $6.45^{\circ} \mathrm{S}$ and $7.25^{\circ} \mathrm{S}$, and longitude $39^{\circ} \mathrm{E}$ and $39.55^{\circ} \mathrm{E}$. It borders the Indian Ocean to the east, and the Coast Region on the other sides. Administratively, the Region is divided into three districts namely Ilala, Kinondoni and Temeke. The climate of the Region is characterized by hot and humid throughout the year with an average daily temperature of $29^{\circ} \mathrm{C}$ and the average rainfall of $1000 \mathrm{~mm}$. The Region is divided into three ecological zones, namely the upland comprising the hilly areas to the west and north of the City, the middle plateau, and the low lands. The main natural vegetation cover in the city includes coastal shrubs, Miombo woodland, coastal swamps and mangrove trees.

Dar es Salaam (Figure 1 below) was preferred since it contains large number of industries with several reported cases of environmental and health threats caused by projects. In addition, the region is where main offices of government authorities, including National Environment Management Council (NEMC), as well as local and international NGOs and Consulting Firms dealing with environmental issues are located. With this location therefore, it is expected that compliance would be ensured compared to other regions. 


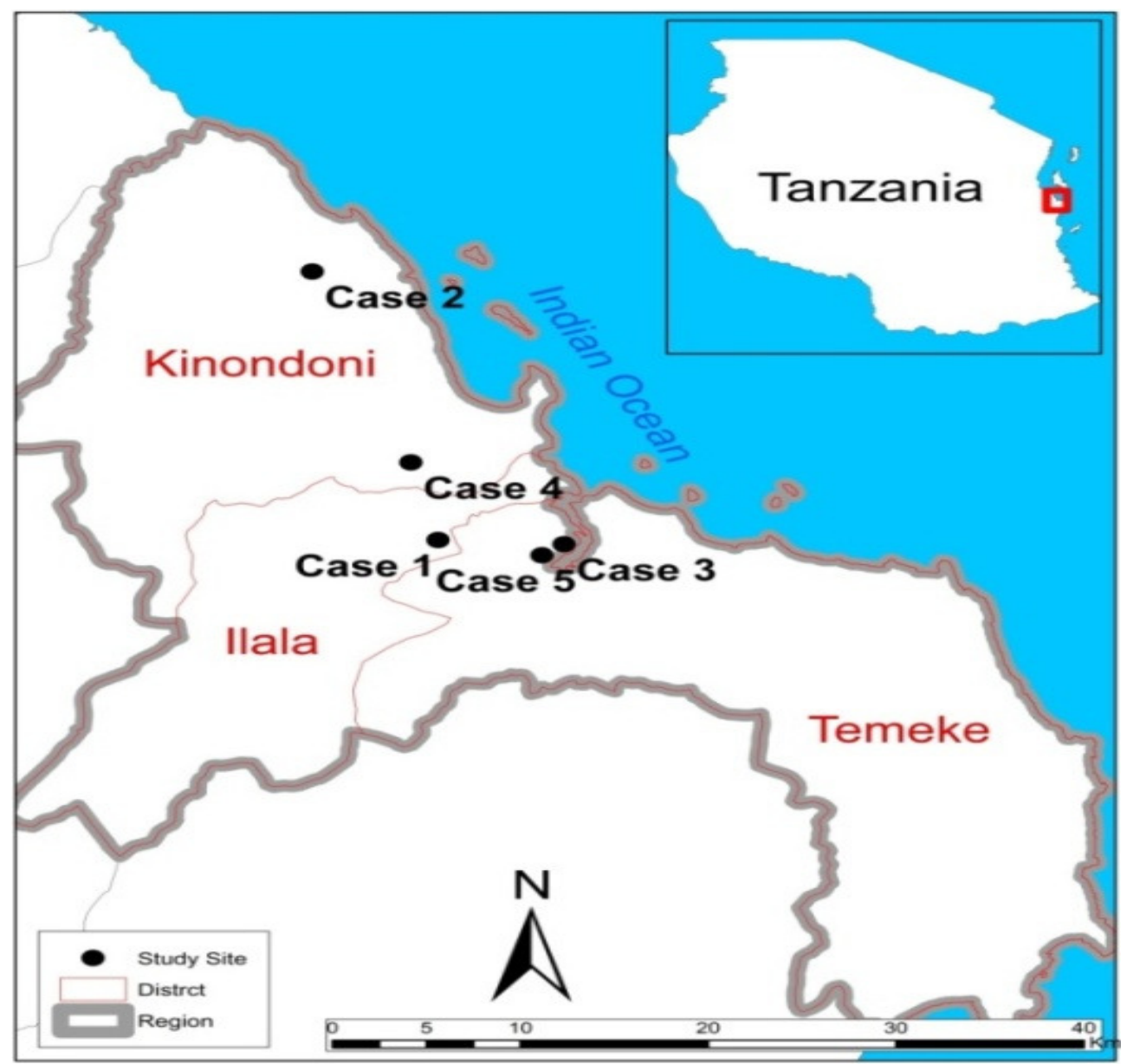

Figure 1: Map of the study area

\section{Methodology}

This study involved five (5) categories of respondents which were purposely selected as they are either involved in EIA implementation or responsible for its enforcement. These categories include; industries with EIA Certificates, NEMC officers, Municipals' Environmental officers, Wards' Health officers, Environmental Consulting firms and NGOs. Purposive sampling enabled selection of respondents which were believed, based on prior information to have required data for the study (Fraenkel and Wallen, 2000). This study involved five (5) industries (i.e. 38.5 percent of those projects which had conducted EIA by then) since EIA was still too young for the country to have a large number of industries with EIA certificates; thus there were only few industries established after the legal status of EIA. In each case the targeted respondents were the top management and staff in the environmental units of the industries. However, the absence of environmental units in actual fieldwork necessitated involvement of top management dealing with environmental issues and staff in the operations units who had on job experience of more than 2 years since they are good indicators of the existence of EIA capacity within industries.

The principal procedure used was to assess compliance to EIA implementation and associated challenges to each case through different methods such as 
documentary analysis, site observation, interview and administration of questionnaire. Thereafter questionnaires and interview guides were used to assess challenges in implementation of EIS recommendation to other groups of respondents. Collection of data from the cases involved firstly documentary analysis to identify the stated environmental impacts mitigation recommendations thereby preparing a list of EIS requirements (i.e. EMP and MP) for each case. Then compliance to the prepared list of EIS requirements is assessed and rated in percentage. The assumption made was that; there is equal weighting of impacts due to the fact that the impacts with low significance are not included in EMP. Therefore each item from the list for each case was ranked depending on the effectiveness of implementation i.e. absence of implementation accorded $0 \%$ while effective implementation was accorded $100 \%$. Thereafter, mean percent for each case was calculated to determine the general compliance in each case.

\section{Results and Discussion}

Performance of EIA with respect to implementation of EIS recommendations was found to be good in some cases and poor in other cases (Figure 1), however, the level of performance is not satisfactory as in most cases it is below $50 \%$. Case 5 had neither EMP nor MP and thus it was only assessed using the general environmental issues. The performance was influenced by different challenges as described in subsections.

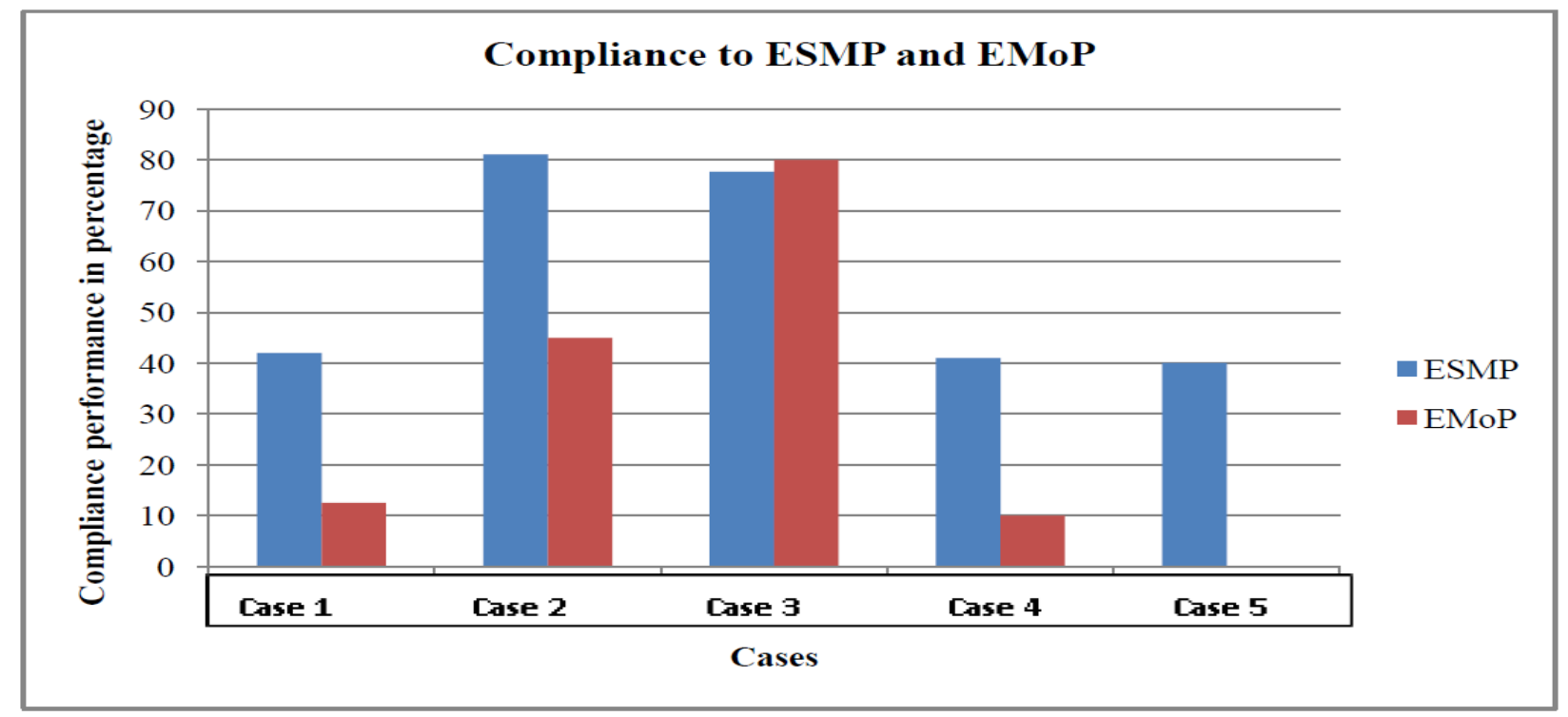

Figure 1: EIA Performance in percentage $(\%)$ by cases studied

\section{Institutional Strength and Weaknesses}

In this study, the institutional strength means capability of the institutions in implementing EIA requirements; institutional weaknesses cause ineffective implementation of EIA.

\section{Status of Industrial Environmental Policy}

Policies formulated by the industries provide a guide on how a particular project can meet its environmental requirements. The study found that 3 cases out of 5 had environmental policies. However, these policies were not known and unclear to workers and thus even specific requirements for their implementation were not known. Despite having policies, there were no initiatives that were planned to implement these policies implying that; availability of the policy alone (i.e. without its implementation) does not 
really meant commitments to improve environmental performance instead a camouflage against lack of environmental management commitment. A study by Pölönen et al. (2011) reported that it is difficult to reach aims of EIA if there is only use of legal obligations and threats of litigation without willingness of the developer to collaborate.

\section{Existence of Environmental Units/Sections}

These sections are responsible for environmental affairs in industries including implementation of EIS requirements. The study did not find any case with environmental section (Table 1). This implies that environmental issues are not institutionalized and seem to be not important to have special section as compared to other issues which were thought to ensure improvement in production and financial gain. However, some cases (cases 2 and 3) had at least good environmental performance as there were workers who were responsible for supervising environmental issues.

Table 1: Existence of Environmental Units/Section in Cases

\begin{tabular}{|c|c|c|c|}
\hline \multirow[t]{2}{*}{ Case } & $\begin{array}{l}\text { Exis } \\
\text { sect }\end{array}$ & environmental & \multirow[t]{2}{*}{ Sections in the industry } \\
\hline & Yes & No & \\
\hline Case 1 & & $\sqrt{ }$ & $\begin{array}{l}\text { Production, Stores, Quality Control, Maintenance, } \\
\text { Quality assurance, Human Resources }\end{array}$ \\
\hline Case 2 & & $\sqrt{ }$ & $\begin{array}{l}\text { Production, Maintenance, } \\
\text { Commercial, Human resources, Finance \& } \\
\text { Administration, and Corporate }\end{array}$ \\
\hline Case 3 & & $\sqrt{ }$ & Engineering, Accounts, Logistics, Sales, Operations \\
\hline Case 4 & & $\sqrt{ }$ & $\begin{array}{l}\text { Bleaching, Dyeing, Printing , Finishing and } \\
\text { Engineering }\end{array}$ \\
\hline Case 5 & & $\sqrt{ }$ & Oily and Soap Section \\
\hline
\end{tabular}

\section{Performance of EIA Compliance Training}

Training programs can be used to build capacity of workers to implement activities recommended in EIS. Study by Marwa (1994) revealed that lack of compliance training for personnel is one among the factors affecting compliance to environmental legislation. This study found that environmental training to workers is either lacking or very minimal. Only case 2 conducted training on introduction to EMS but it was conducted solely at managerial level. Training which does not involve workers who are responsible for implementation of EIA activities makes EIA recommendations un-implementable. Consequently, most of the workers were unaware of EIA requirements as none of them attended in-job training on environmental issues. Unlikely, safety training especially training on fire fighting and prevention (as part of occupation health and safety) was somehow given priority in all cases.

\section{Status of Annual Environmental Audit}

Annual environmental audit can be used to indicate compliance to EIS requirements. Section 50 of EIA and Audit Regulations of Tanzania states that; "after the EIS has been approved by the Minister, or after initial audit of an on-going project, the developer is required to take all practical measures to ensure implementation of EMP by carrying out self-audit annually and preparing an environmental audit report after each audit and submitting the report to the Council annually or as may be prescribed by the Council". Despite of this requirement, 
Performance of Environmental Impact Assessment (EIA) Regime in Tanzania.................NYIHIRANI et al.

performance of annual environmental audit was found to be poor in all cases as none of them submitted the report to the Council. Only case 3 conducted annual self-audit and prepared a report while case 2 stated to be unaware on requirement of submitting the report to the Council, despite the fact that this requirement is printed at the back of the environmental certificate. The Council revealed similar performance that only few projects submitted their annual environmental audit reports; and even those which submitted, their environmental performance was still not satisfactory. Similarly Panigrahi and Amirapu (2012) revealed that self-monitoring and reporting system indicated in EMPs are rarely practiced by project proponents thus non compliance which cause many community complaints On environmental quality.

\section{Effectiveness of follow up to EIS compliance}

Follow up to the projects granted EIA certificates helps in ensuring conformity with environmental agreement. Section 57 of EIA and Audit Regulations requires that "Council to monitor the operations of the industries with a view of determining immediate and long term effect on environment and monitor on-going projects on a continuous basis". Despite of this clear legal requirement, this study found that follow up on EIA compliance to projects with EIA certificates is still not satisfactory. There were only 2 cases monitored, one of them was monitored only once while the other was monitored to review the certificate. In line with this, the study found that; the Council and Municipal Councils were not conducting monitoring to check EIA compliance. The same scenario has been reported by a number of authors (e.g. Ahmad and Wood, 2002; O'Faircheallaigh, 2007; Marara et al., 2011) that EIA follow up is a weakness even in other countries.
Ramjeawon and Beedassy (2004) reported that if there is no systematic follow up to decision making, EIA may become just a paper chase to secure a development permit rather than a meaningful exercise to bring about real environmental benefits. EIAs are carried out just as a formality since they may either take place even after start of construction (Panigrahi and Amirapu, 2012). Therefore, ineffective follow up cause lower compliance. This study found lack of resources to be one among the constraints that hinder responsible institutions to make frequent follow ups. It is quite difficult for the staff available in responsible authorities to handle the total number of studies submitted reliably (Androulidakis and Karakassis, 2006). Similar observation has been reported by Albina (2008) and Marara et al. (2011) that ineffective follow up is due to inadequate funding and understaffing of the EIA authorities for the regulation and enforcement of EIA activities. In Municipals, environmental units were still new and thus they were still building capacity to facilitate incorporation of the environmental issues. However, industries are mandated to carry self-audit at their own expenses and regulatory authorities are only supposed to review them.

Effectiveness of coordination between institutions

Effective coordination between the Council and other institutions with a responsibility of follow up or issuing permits to new projects is very important in EIA performance. Such institutions include the Tanzania Investment Centre (TIC), Ministry of Trade and Industry, Business Registration and Licensing Agency (BRELA), Energy and Water Utilities Regulatory Authority (EWURA), Municipals, and Districts among others. This study found that there is ineffective institutional coordination in environmental management. This creates loopholes for projects being established and 
starts operation without incorporation of EIA aspects as the Council is at times not consulted prior issuance of permits. Panigrahi and Amirapu (2012) reported that lack of coordination leads to the start of the developmental projects prior to getting EIA clearance. For instance, Sosovele (2011) found that many building permits for projects falling under mandatory EIA list were issued without conducting EIA. Lack of harmonized institutional arrangement with a clear and properly co-ordinated flow of events guarantees a continued contradiction in approval processes (Katima, 2008). It is easier for the Council to introduce the issue of EIA requirement prior to designing stage rather than applying punishment to violators after construction phase.

Equally important, coordination easier a duty of follow up to projects with EIA certificates. It is difficult for the Council to conduct frequent follow up due to the large area which it has to deal with; consequently it takes longer time between consecutive visits to a particular project or waiting until hearing public complaints. Moreover, the low level of autonomy of responsible authorities may pose a challenge in enforcing EIA policies and procedures (Marara et al., 2011). For instance NEMC rejected the prawn project but the government approved it without making any consultation (Katima, 2008).

\section{Awareness of workers in implementation of $\boldsymbol{E I A}$}

Awareness of staff of the project on EIA requirements as per EMP and MP is important as it tells what to implement. However this study found that cases 2 and 3 were conversant on the EIA requirements in their projects while others had only general idea on EIA because of EMA enforcement. Low awareness was due to lack of background experience and training on environmental issues.

Moreover, workers will also be unaware if EIS remains only at shelves without any capacity building at the shop floor level. This study found that only 5 workers out of 25 had general idea on EIA while others were unaware even on the term itself. Low awareness implies that there is ineffective compliance. Similar observation was reported in the study by Katima (2008) and Marara et al. (2011) that lack of awareness is a hindrance in EIA regime. Accordingly, this study found that cases with good compliance are the ones which were well conversant on EIA requirements of their projects. Therefore understanding of EIA is one amongst the main challenges for successful EIA implementation (Sadler, 1996).

Resources allocation in implementation of $\boldsymbol{E I A}$

Resources such as human, fund and equipments allocated for implementation of EIA activities are important in EIA compliance. This study found that, only cases 2 and 3 had officers who deal specifically with environmental issues within their projects. It was also found that cases with such officers showed good compliance compared to those which lack such employees. Similarly, Ramjeawon and Beedassy (2004) found that lack of human resources is one of the impediments of EIA implementation. However; existence of environmental officers alone without coofficers to execute environmental activities makes implementation of EIA requirements difficult, since it is supposed to be a team effort.

Allocation of dedicated funds for executing environmental activities easier compliance to EIA requirements rather than asking fund from general budget of the project. Section 18(1) of EIA and Audit Regulations requires the costs associated with implementation of the mitigation measures and monitoring plan to be incorporated in EIS. Furthermore EMPs and MP contain estimated costs for implementing the monitoring and mitigation measures. 
However, proponents have a conception that EIA results in unreasonable economic burdens (Pölönen et al., 2011); and internalization of the environmental cost is a hindrance to economic growth (Aslam, 2006). This study found that; none of the cases allocated special budget for environmental activities and EIA activities per se even after committing themselves to implement the EMP and MP. This implies that costs incorporated in EIS were only meant for certification but not intended for implementation.

Nevertheless, only 2 cases (case 2 and 3 ) showed the need to allocate dedicated budget reasonably it is required by law; others (case 1, 4 and 5) thought it was not important with reasons that their projects were very small and not very much polluting. Cases with higher compliance were the ones which showed concern on the need to allocate dedicated budget. This implies that willingness and commitment to allocate fund for EIA implementation plays a greater role in EIA compliance. Study by Aslam (2006)

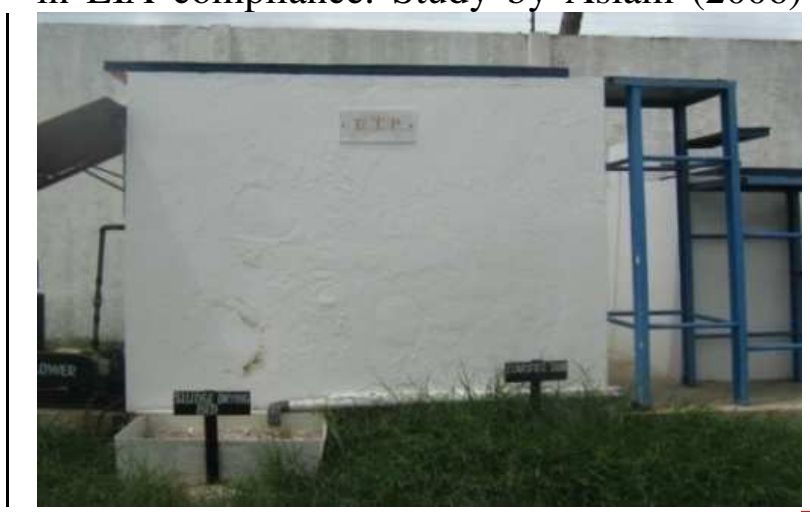

Plate 1a Fluidized Aerobic Bio Reactor (FAB) suggests that the cost incurred for EIA cannot produce any significant change in the overall project costs

This study found the presence of wastewater treatment facilities and air pollution control devices which differ in terms of quality (Plate $1 \mathrm{a}$ and b; Table 2). There were also special place for keeping solid wastes which were then collected by people contracted by the projects and some used pieces of logs as sources of energy. However, presence of equipments alone cannot show compliance without assurance of their functioning and performance. Panigrahi and Amirapu (2012) revealed that after EIA approval there is less concern by proponents in adoption of mitigation measures, those adopted do not maintain the equipments so installed. The study found that, in most cases, there was no monitoring of the effluent and emissions for ensuring compliance. For instance there were complaints about colour drain of effluent and bad 11 of exhaust air from case 4 and case 1 , respectively.

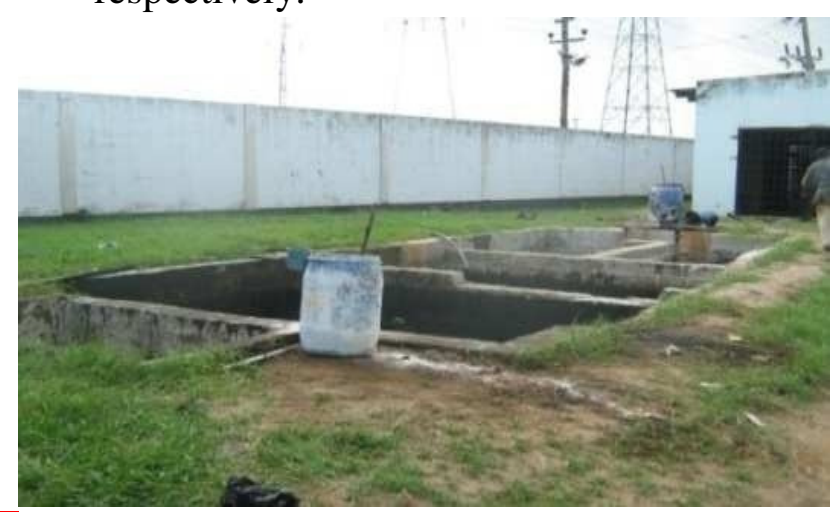

Plate 1b Waste Stabilization pond

Table 2: Equipment used by cases

\begin{tabular}{|l|l|l|l|l|l|}
\hline Cases & Equipments available for EIA implementation \\
\cline { 2 - 6 } & $\begin{array}{l}\text { Wastewater } \\
\text { treatment }\end{array}$ & $\begin{array}{l}\text { Air } \\
\text { pollution } \\
\text { control }\end{array}$ & $\begin{array}{l}\text { Solid waste } \\
\text { management }\end{array}$ & $\begin{array}{l}\text { Noise and } \\
\text { vibration } \\
\text { Control }\end{array}$ & Safety gears \\
\hline Case 1 & FAB bioreactor & $\begin{array}{l}\text { Filters such } \\
\text { as } \\
\text { HEPA }\end{array}$ & Plastic bags & No measure & $\begin{array}{l}\text { Only boots } \\
\text { and coats to } \\
\text { some workers }\end{array}$ \\
\hline Case 2 & $\begin{array}{l}\text { Not mentioned in EIS in } \\
\text { operation }\end{array}$ & $\begin{array}{l}\text { Fabric } \\
\text { filters, }\end{array}$ & $\begin{array}{l}\text { Not } \\
\text { mentioned }\end{array}$ & No measure & $\begin{array}{l}\text { All required } \\
\text { gears }\end{array}$ \\
\hline
\end{tabular}




\begin{tabular}{|l|l|l|l|l|l|}
\hline Case 3 & $\begin{array}{l}\text { Oil water separator, } \\
\text { drainage for storm water, } \\
\text { wastewater }\end{array}$ & $\begin{array}{l}\text { Floating } \\
\text { cover }\end{array}$ & $\begin{array}{l}\text { Not EIS in } \\
\text { operation } \\
\text { mentioned } \\
\text { in EIS }\end{array}$ & $\begin{array}{l}\text { Not mentioned } \\
\text { in operation }\end{array}$ & $\begin{array}{l}\text { All required } \\
\text { gears } \\
\text { Available }\end{array}$ \\
\hline Case 4 & Stabilization pond & $\begin{array}{l}\text { Extraction } \\
\text { fans }\end{array}$ & Bins & No measure & Only coats \\
\hline Case 5 & Oxidation ponds & $\begin{array}{l}\text { Extraction } \\
\text { fans }\end{array}$ & Plastic bags & No measure & $\begin{array}{l}\text { Only coats to } \\
\text { some workers }\end{array}$ \\
\hline
\end{tabular}

Likewise, availability of safety gears was found to be not satisfactory as workers in operation units were observed either wearing incomplete set of safety gears or not wearing them at all. Presence of waste treatment facilities at project sites is due to the fact that, the issue of waste treatment facilities especially wastewater discharge is currently an alarming issue to be tagged for inspection by the government due to community complaints; unlike complaints on unavailability of safety gears from few workers within a particular project. The problem of inadequacy of resources for implementation of EIA was also reported by Environmental NGOs and Consulting Firms.

\section{Conclusion}

From the preceding discussion it can be concluded that EIA performance is still not satisfactory in Tanzania. Amongst the challenges that influence performance of EIA are institutional weaknesses, low awareness of workers as well as inadequate resources allocation. It was found that institutional weaknesses which lead to poor EIA compliance was due to: ineffective institutional coordination in ensuring EIA compliance to projects with EIA certificates, ineffective monitoring and follow ups, absence of projects' environmental policy, lack of projects' annual environmental audit, absence of environmental sections, and lack of EIA compliance capacity building to project workers. Top management are unaware of the existence of the EMP meaning that conditions attached to EIA Certificate are not addressed. Almost all staff did not have knowledge of the existence and implementation of EIA by the project. Furthermore, no dedicated budget line for the implementation of EMP was found in almost all projects. Most of the projects do not have officers specifically responsible for environmental management activities. These challenges generally gave a clear picture that weak institutional arrangement and lack of enforcement are the main hindrance factors to EIA performance in Tanzania, as such EIA remains a procedural process rather than being a tool for environmental management.

\section{Recommendations}

Based on the identified challenges to EIA performance, the following recommendations can be drawn

There is a need of introducing incentives for those who will perform well and enforcing punitive scheme to violators in complying with EIS recommendations including submission of Annual Environmental Audit Report. Not only that but also there is a need of adding requirement of employing competent staff to supervise environmental issues within a project as specific condition of EIA certificate. On top of that, environmental units should be established; projects should be required to build capacity of their staff in issues related to environmental management according to the EMP and MP. 
Responsible institutions should make frequent visits to projects with EIA certificates to monitor EIA compliance including presence and performance of treatment facilities as well as safety gears to workers as recommended in EIS. However, this needs a support from the government to capacitate in terms of resources. To easier the task, Municipals and Wards should make follow up to the projects within their jurisdiction and report to the Council. However there are no environmental experts at ward level therefore there is a need of either employing ward environmental officers or train the existing ward health officers. This calls for thorough need to put into practice section 39 of EMA which requires designation of the Township, Ward, Village, Mtaa and Kitongoji Environmental Management Officer. Also, the issue of low staff level can be mitigated by the Council to outsource some activities. Moreover, there is a need to strengthen public hearing systems particularly to communities living close to particular project site

There is a need to strengthen institutional coordination between the Council and sectors having authority of issuing licenses to projects, and other sectors with the responsibility of making follow up as stipulated in EMA. This should involve inclusion of EIA aspect as among the precondition of obtaining the permit in every permitting authority; establishing environmental desks in those authorities and facilitating the officers within the established desks to work effectively in assuring consideration of environmental permit to each project. Furthermore, there must be frequent communication between the Council and officers within the established environmental desks.

\section{References}

Ahmad, B. and Wood, C.M. (2002). Environmental Impact Assessment in Egypt, Turkey and Tunisia. Environmental Impact Assessment Review, 22: 213-234.

Albina, J. (2008). Assessment of EIA status and its implementation for selected projects in Tanzania. MIWRM Dissertation, University of Dar es Salaam.

Androulidakis, I. and Karakassis, I. (2006). Evaluation of the EIA system performance in Greece, using quality indicators. Environmental Impact Assessment Review, 26: 242-256.

Aslam, F. (2006). Environmental Impact Assessment in Pakistan, Overview of Implementation and Effectiveness, KTH Architecture and the Build Environment

Booth, V., Chapman, K. and Walmsley, B. (n.d), Tanzania, Retrieved from http://www.saiea.com/saieabook/tanzania1.pdf

Curran, J.M., Wood, C. and Hilton, M. (1998). Environmental Appraisal of UK Development Plans; Current practice and future directions. Environ Plann, 25(3): 411-433.

Fraenkel, J.R. and Wallen, N.E. (2000). How to Design and Evaluate Research in Education, $4^{\text {th }}$ Edition, Toronto Boston, McGraw Hill.

Hazell, S. and Benevides, H. (2000). Toward a legal framework for SEA in Canada, Perspectives on Strategic Environmental Assessment, Lewis, New York, USA.

Katima, J.H.Y. (2008). Environmental Impact Assessment: for whose needs? Retrieved from http://www.unep.ch/etu/publications/26 \%29\%20183\%20to\%20191.pdf 
Kiely, G. (1998). Environmental Engineering, McGraw Hill Companies, UK.

Marara, M., Okello, N., Kuhanwa, Z., Douven, W., Beevers, L. and Leentvaar, J. (2011). The importance of context in delivering effective EIA: Case Studies from East Africa. Environmental Impact Assessment Review, 31: 286-296.

Marwa, P. (1994). Environmental Pollution in the Manufacturing Sector in relation to Industrial Development, Ceest Research Report.

O'Faircheallaigh, C. (2007). Environmental agreements, EIA follow-up and aboriginal participation in environmental management: The Canadian experience. Environmental Impact Assessment Review, 27: 319342.

Panigrahi, J.K and Amirapu, S. (2012). An assessment of EIA system in India, Environmental Impact Assessment Review, 35: 23-36.

Pölönen, I., Hokkanen, P. and Jalava, K. (2011). The effectiveness of the Finnish EIA system-What works, what doesn't, and what could be improved? Environmental Impact Assessment Review, 31: 120-128.

Ramjeawon, T. and Beedassy, R. (2004). Evaluation of the EIA system on the
Island of Mauritius and development of an environmental monitoring plan framework. Environmental Impact Assessment Review, 24: 537-549.

Sadler, B. (1996). Environmental Assessment in a Changing World: Evaluating Practice to Improve Performance; International Study of the Effectiveness of Environmental Assessment, CEAA and IAIA.

Sosovele, H. (2011). Governance challenges in Tanzania's environmental impact assessment practice, African Journal of Environmental Science and Technology, 5: 126-130.

Tesli, A. (2003). World Development Report 2003, Dynamic Development in a Sustainable World, The use of EIA and SEA relative to the objective of sustainable development, Norwegian Institute for Urban and Regional Research, Oslo.

URT, (1997). National Environmental Policy, Office of the Vice-President, Dar es Salaam

URT, (2004). Environmental Management Act, Office of the Vice-President, Dar es Salaam

URT, (2005), Environmental Impact Assessment and Audit Regulations, Office of the Vice-President, Dar es Salaam. 